\title{
Identification of factors affecting reverse chain performance in relation to customer satisfaction using ISM Modelling \& MICMAC Analysis
}

\author{
Rupesh Kumar Tiwari*
}

Pursuing M.Tech in Industrial Engineering from CSVTU, Bhilai- India

\section{CHRON I C L E A B S T R A C T}

Article history:

Received June 10, 2013

Received in revised format 25 July 2013

Accepted August 222013

Available online

August 232013

Keywords:

ISM

MICMAC analysis Reachability

Matrix

Transitivity

Diagraph

\begin{abstract}
Reverse Logistics has become buzzword in today's industrial word and big differentiating factor in quest of success for any organization word wide. Whole world is suffering from scarcity of resources and we have finite area available for the waste disposal. One of the sustainable solutions is to design product in such a way so that we can maximize its reuse through reverse logistics. Reverse logistics is fast becoming industrial design standard for majority of organizations worldwide. Reverse logistics has become a need of an hour. Some of the organization do it voluntarily and some because of the environmental rules and legislations. In order to achieve total customer satisfaction, one has to take care of product for its entire life cycle through activities of reverse logistics. In this research I tried to investigate the factors affecting performance of reverse logistics in relation to customer satisfaction. I have used interpretive structural modelling technique to understand the complex pattern of contextual relationship amongst the most important factors through diagraph, which explain performance of reverse logistics in relation to customer satisfaction. I have also used MICMAC analysis to classify these factors according to their driving power and dependency power. MICMAC analysis facilitate in identification of most important factors in explaining performance of reverse logistics in relation to customer satisfaction. Further this research may helpful in reverse logistics design process planning, driven by customer requirement.
\end{abstract}

(C) 2013 Growing Science Ltd. All rights reserved.

\section{Introduction}

Resources are scarce in nature and we got limited disposal capacities. Sometimes it is economical to reuse the product rather going for its disposal. Growing environmental concern and population emphasizes the reuse of products and materials. Some of the countries have gone to extent of charging manufacturer for the entire life cycle of their product. In near future the worlds is going to witness explosive growth of product recovery activities and at the same companies are recognizing opportunity to access this new market segment combining with environmental stewardship.

The focus of product recovery is more on engineering and its logistics issues has been ignored. It is only in the recent past need to investigate logistics aspects of product recovery and unsold

* Corresponding author. Tel: +918109470069

E-mail addresses: rupeshtiwari9999@gmail.com (R. K. Tiwari)

(C) 2013 Growing Science Ltd. All rights reserved.

doi: $10.5267 /$ j.uscm.2013.08.005 
merchandise have been acknowledged. The concept of reverse logistics was newly added to Supply Chain Operation Reference Model (SCORE), recognizing its importance for efficient and effective supply chain management in future. Some of the companies are forced to take the product back while others do it willingly recognizing the value in the used product. Thus the reverse logistics has become an important parameter to judge the efficiency and effectiveness of the modern supply chain.

Like any other concept, the reverse logistics is also kept continuously evolving over the period of time. The new concept of reverse logistics is different from traditional concept as process of recycling product. The new definition is comprehensive and wider in scope. Reverse logistics is defined as "The process of planning, implementing, and controlling the efficient, cost effective flow of raw materials, in-process inventory, finished goods and related information from the point of consumption to the point of origin for the purpose of recapturing value or proper disposal (Dale \& Ronald, 1999)"

Reverse logistics can be used to enhance the organization's customer service capabilities. By communicating and convincing the message to the market place your organization can add to the stature of the organization.

\section{Benefits}

In general, regardless of the stature of the organization, the following is the most far and wide recognized benefits derived from reverse logistics

- Improved customer contentment and retention.

- Reduction in the acquisition of parts and subassemblies.

- Enhance revenue and profitability of organization through increased availability of product/service.

- Improved efficiency and effectiveness of the organization, which led to significant improvement in the efficiency of the organization.

- Improved time bound sensitivity towards listening to the voice of the customers.

- Results in anticipation of needs and wants of the customer much ahead before actually they could actually realize it.

- Development of intellectual and emotional bonding with the customers which led to a belief that they made right choice in selecting you.

- Development of interactive partnership with the customer instead of proactive or reactive partnership with the customer.

Understanding factors affecting reverse chain performance in relation to customer satisfaction is a complex problem. The complexity of the problem is due to presence of large number of factors and interaction amongst the factors. Identification of these direct and indirect factors is a tedious job. Hence it becomes imperative to have some scientific methodology well assisted by the software and proposed Interpretive structural Modelling could be one of the solutions. Further Cross-Impact Matrix Multiplication Applied to the Classification analysis (MICMAC) is used for structural analysis of the system to classify the factors in various categories according to the driving power and dependence power of these factors.

\section{Literature Survey}

Increased competition in today's globalized world and shrinking technological life cycle is the prime driving force making companies to think about some differentiating factors such as reverse logistics as an performance enhancing strategy with regards to customer satisfaction in particular Richey et al. (2005). Most of the finding it difficult to cope up with the ever growing expectations of customers from the service provider with regards to their return policies (Autry \& Daugherty, 2001). Reuse of 
products and materials is not a new happening, recycling of waste papers, used plastic bottles and metal scrap are some of the examples to quote (Fleishmann, 1997). The recognition and exploiting reverse logistic as a comprehensive tool to enhance the firm's competitive performance is relatively a new concept. Since last two decades only some research have been done in the field of reverse logistics and the pool of the knowledge is slowly developing (Rogers \& Tibben-Lembke, 2001). Although some research have been done in reverse logistics but majority of the companies are yet to reap the benefits of it. It is often view as non-value added activity and expensive. According to survey which have been carried out over the years in USA and western Europe majority of companies feel that return management is not important and there is no strong reverse logistics program (Zeiger, 2003). Such a kind of deliberate ignorance of corporate world towards the reverse logistics is difficult to understand (Richey \& Genchey, 2005). Different from corporate world the field of reverse logistics is matter of great curiosity and interest for many of the researcher worldwide as early as 1993 ever since Heine and Byrne (1993) had published an article with "reverse logistics" title. The article published by Rogers \& Tibben-Lembke titled "Going Backward: Reverse Logistics Trends and Practices" powered the growth in research related to reverse logistics. Though large number of research carried out in the recent past on reverse logistics suggest its tremendous potential in enhancing firm's competitive performance and customer satisfaction, however the value of reverse logistics is often overlooked by the corporate. Company's management needs to keep close eye over something which take away the potential profit, dissatisfy the customers and put a drain over the firm's scarce resources (Carter \& Ellram, 1998; Blumberg, 1999; Dowlatshahi, 2000; Rogers \& Tibben-Lembke, 2001; Mason, 2002). So it is becoming imperative for the corporate world to effectively and efficiently handle the reverse logistics issues. Now the corporate world wide started to realize the importance of reverse logistics and its potential benefits to gain efficiency and effectiveness in their supply chain operations. They started to use reverse logistics as value added centre and use their reverse process as differentiator. This results in increased market share, revenue and reduction in the inventory cost (Daugherty et al., 2002). Some of the organizations are gone to the extent of using reverse logistics process as a tool to ensure total customer satisfaction by customer's needs and wants are listen and cared for its entire life cycle (Mason, 2002). During the recent past the corporate world has witnessed significance increase in the reverse flow of used products and materials for disposing, recycling, remanufacturing, reselling and repair (Stock, 2001). Slowly but steadily corporate world is stared to realize reverse logistics as a key strategic issue which is instrumental in achieving eluding target of Total Customer Satisfaction (Mollenkopf \& Russo, 2007).

\subsection{Drivers of reverse logistics}

Some of the companies are going for reverse logistics by recognizing the great value of it, some of them doing it because they have to and some are socially motivated to do so. By and large the main driving force behind Reverse logistics can be categorized as follows,

1. Economic Profit

2. Environmental rules and regulations

3. Corporate social responsibility

\subsection{Frame Work}

The nature of reverse logistics is quite different from conventional logistics. The following are the prime characteristics of reverse logistics.

- We do not know and predict accurately when the product is likely to be returned or disposed.

- Random and wide variety of return product with uncertain quality.

- Return flow will depend upon the end users. 
- Because of uncertainty of returned mercantile, its planning, routing, scheduling and processing become difficult.

- Potential value of returned mercantile is uncertain and we need to maximize the value of returned asset.

- Returned assets need to be sold in the secondary market but, its demand is uncertain and pricing become difficult.

Organization product return policy is the part and parcel of its service package. This further increases the importance of reverse logistics in managing the returned product issues. This unique characteristic of reverse logistics led many researched to study its key elements, task associated, drivers and process of decision making in the environment of reverse logistics (French \& Discenza, 2006).

There has always been a trade-off between performance of reverse logistics and its cost. Reverse logistics managers need to strike a balance between Reverse Logistics performance and cost of providing it. The ultimate goal is to maximize the economic performance. Thus the economic performance can be an effective measure of firm's reverse logistics capabilities. The performance of reverse logistics depends on two major factors of operational responsiveness and operation service quality.

Operational responsiveness is the ability of the business process to respond to changing conditions, which results in greater efficiency and reduction of the risk. Operational responsiveness is possible when we have complete information about the business environment which is necessary to take decisions at every level. Operational responsiveness is basically the agility of reverse logistics. Agility happens when we are in a position to analyse the customer behaviour patterns and able to anticipate potential problems to resolve it at the least possible time. Operational service quality means conformance to the customer requirement including timeliness of repair and rework of returned products (Rogers \& Tibben-Lembke, 2001). Extent of reverse logistics activities varies according to industry where the firm operates and its channel position.

The field of reverse logistics is so vast that cut across several functions of the organization. Researchers are focussing on holistic view of the reverse logistics and their research work wrap entire process of reverse flow. For example: Forecasting of sales need to be fine-tuned by taking into the account of uncertainty and bulk of return material. Bill of material needs to be restructured to meet the challenges of reverse logistics (Krupp, 1993). Some of the research have focussed on aspects of product handling in reverse logistics including transportation, material handling, inventory management and distribution (White, 1994). Some of the researchers have gone to the extent of viewing reverse logistics as an opportunity for effective differentiation and competitive advantage (Dave, 2005). Dawe (1995) suggested in his research a need of reengineering of the return process for the breakthrough improvement in the return process and gain competitive advantage. Increasing environmental concern worldwide and scarcity of raw material compelling organization to find value in the returned material and look to reuse it. Return process is fast becoming the integral part of the value chain. There cannot be any universal definition of reverse logistics. Definition of reverse logistics varies from company to company and largely depends on how the company is going to exploit process of reverse logistics for value addition. Therefore, it has become imperative to analyse the holistic view of reverse logistics.

The benefits we derive by managing our return process effectively and efficiently are by and large qualitative in nature. Many researchers over the years tried to develop a quantitative model of reverse logistics. These models can of immense importance to improve the process of return management including its feasibility in remanufacturing operation (Clegg et al., 1995). Reverse logistics is fast becoming the top management priority due to its potential value and effects on customer satisfaction. Reverse logistics gives us great opportunity to understand customer's and by maintaining healthy 
relationship their loyalty can be ensured (Richey \& Genchey, 2005). Since the reverse logistics is different from conventional logistics and will require some additional resources to improve the service quality and performance of the firm. Efficient and effective reverse logistics is having tremendous potential in improving economic performance and relationship with the customers. Reverse logistics management consumes lot of resources during its maintenance and implementation and we need to commit significant time and resource (Autry \& Daugherty, 2001). Customer loyalty is the direct outcome of the service quality of the reverse logistics program. Customer satisfaction is the intermediary of apparent service quality and customer loyalty. So it has become important to investigate the resource commitment in resource logistics and customer satisfaction. Creating value through reverse logistics program has been focal point of the many of the researcher worldwide. The role of information processing in reverse logistics and improvement in its service quality cannot be ignored. Rapid growth in technologies related to communication and information can be leveraged for improving the efficiency and effectiveness of reverse logistics.

Curiosity in the field of reverse logistics is on the rise rapidly as many types of businesses distinguish it as a vital part of the overall supply chain. Conventionally, reverse logistics has engrossed little attention, as organizations focused on the forward moving supply chain including marketing, sales, procurement, manufacturing, and distribution. The mechanism that sparked this interest in reverse logistics has been environmentalism. Reverse logistics practices have often been environmentally driven, particularly in European countries such as Germany, where environmental norms are more stringent than in the U.S. However, many organizations are discovering that recuperating their reverse logistics processes can be a value-added proposition that may or may not have anything to do with environmental concerns. The added value could be attributed to improved customer service leading to increased customer retention and sales. The added value could also be through reduced cost and/or reduced cycle time. It involves a direct marketer that is considering an innovative reorganization of its returns process in order to increase the convenience of the process, while reducing the cycle time.

Products flow in the reverse direction in supply chains- from consumer to producer-every day. In some industries, over $20 \%$ of all goods that are sold are eventually returned to the seller (Rogers \& Tibben-Lembke, 1999). As a result, some firms are implementing reverse logistics programs to lever the returned goods. However, many firms appear to have no formal reliable game plan in place to deal with returns. In one recent study, more than a third of survey respondents indicated that inadequate and/or misdirected formal policy represents a major hurdle to reverse logistics program success (Merritt, 2001). Taking into deliberation that process formalization is generally believed to be related to firm performance (Walker \& Ruekert,1987), and given the enormous volumes of returns modern companies face, the lack of formalized reverse logistics programs/ processes is rather surprising. In general, formalization of business processes such as reverse logistics can improve firm efficiency by standardizing recurring activities and transactions (Rukert et al., 1985). This is especially true in the modern hypercompetitive marketplace, where firms strongly compete on the basis of customer service, and as a result are more moderate than ever before in allowing returns (Morten \& New, 1998). Many firms will accept almost anything sent back up the channel, regardless of reason or condition, if they perceive that doing so could benefit the customer relationship (Merritt, 2001). However, while reverse logistics volume/demands may be difficult to predict, the mechanism of a reverse logistics system-involving bringing product back or arranging alternate disposition-can be routinized. Thus, reverse logistics, by its very nature, would seem to be an ideal candidate for developing formalized methods of handling. Effective reverse logistics focuses on the backward flow of materials from customer to supplier (or alternate disposition) with the goals of maximizing value from the returned item and/or assuring its proper disposal (Rogers \& Tibben-Lembke, 1999; Stock, 1998). This may include product returns, source reduction, recycling, materials substitution, reuse of materials, waste disposal, refurbishing, repair, and remanufacturing Stock (1998). Reverse logistics processes-and reverse logistics research-has traditionally emphasized green logistics, i.e., the use of 
environmentally conscious logistics strategies (Carter \& Ellram, 1998; Morten \& New, 1998; Murray, 2000; Van Hock, 1999). While environmental aspects of reverse logistics are critically important, many firms are also recognizing the economic impact of reverse logistics (Klausner \& Hendickson, 2000; Richey et al., 2000). Recent research suggests that companies can recapture value through an efficient and effective returns process (Autry \& Daugherty, 2001). Effective reverse logistics is believed to result in improved firm outcomes. Firms that effectively manage the reverse flow of goods benefit through decreased resource investment levels and cost reductions, i.e., storage and distribution (Andel, 1997; Giuntini \& Andel, 1995). Additionally, reverse logistics-related remanufacturing, repair, reconfiguration, and recycling have been shown to impact a company's bottom line through value reclamation (Andel, 1997; Giuntini \& Andel, 1995; South, 1998; Clendenin, 1997). Quick and efficient handling of returned product can also be critical in sustaining relationships and creating repeat purchases. For this reason, firms are more willing than ever to accept returns from customers. Reverse logistics allows firms an opportunity to differentiate themselves, builds consumer confidence in the company brand, and positively influences customer satisfaction (Blumberg, 1999). As a result, liberal return policies have become a standard marketing practice and a major component of the corporate image for many firms in both business-to-business and businessto-consumer markets. The complexity of managing damaged or defective merchandise, product recalls, maintenance, repairs, and recycling should make reverse logistics programs a high priority.

Formalization refers to the extent to which control mechanisms such as rules, processes, or procedures guide intra-firm or inter-firm (i.e., supply chain) operations (Rukert et al., 1985; Van \& Ferry, 1980). Generally, formalization implies that control mechanisms take the form of written regulations or contractual obligations (Van \& Ferry, 1980). Within the current context, this means that suppliers who are highly formalized will have standard operating procedures for reverse logistics before they are needed. For example, they may provide instructions to their customers specifying how returned merchandise is to be shipped (Indian Postal Service), who pays for the shipping costs, and where to return merchandise (manufacturer's facility, retailer's distribution centre, etc.). With a highly formalized organization, the approach to handling specific returns-related events is defined in advance. Formalization of control mechanisms has been associated with increased efficiency in operations occurring both within and between firms (Walker \& Ruckert, 1987; Rucker et al., 1985). Internal operations are formalized and thereby made more efficient through the establishment of workplace rules or standard operating procedures. Alternatively, formalization of external operations leads to efficiencies by defining firms' reciprocal expectations in detail, e.g., a written contract, such that misunderstandings and other problems among trading partners are minimized (Ruckert et al.,1985). Formalization has been recognized as a key attribute in firms that are considered to be leading-edge in terms of logistics practices. Bowersox et al. (1992) stated that formalized control mechanisms allow logistics operations to realize advantages in terms of efficiency. According to Bowersox and Daugherty (1992) "Formalization is a strategy of control that provides a structure for directing logistics operations". Traditional organizational research suggests that a high level of formalization may inhibit innovation. This was not found to be the case in terms of logistical performance. In logistics, formalization improved operating flexibility and the achievement of operating efficiency. Efficiency is improved because formal rules and procedures eliminate the need to treat every event as a new decision. Hence, the establishment of formalized logistics programs is thought to have an effect on firm-level logistics program performance (Bowersox \& Daugherty, 1992).

\subsection{About Interpretive Structural Modelling (ISM)}

ISM is an interactive modelling technique. In this technique, a set of diverse, directly and indirectly related elements are structured into an inclusive methodical model (Sage, 1977; Warfield, 1974). The model so formed exhibits the structure of a complex issue or problem in a cautiously designed outline implying graphics as well as words (Shanker \& Suhaib, 2007; Ravi \& Shanker, 2005; Singh et al. 2003). 
Interpretive structural modelling (ISM) is a well-recognized methodology for spotting associations amongst specific items, which define a problem or an issue. For any composite problem under deliberation, a number of factors may be related to an issue or problem. However, the direct and indirect associations among the factors describe the circumstances far more precisely than the individual factor taken into separation. Therefore, ISM gives insights into combined perceptive of these associations. ISM starts with an identification of variables, which are pertinent to the problem or issue, and then expands with a group problem solving technique. Then a contextually relevant subordinate relation is chosen. Having decided on the element set and the contextual relation, a structural self-interaction matrix (SSIM) is developed based on pair wise assessment of variables. In the next step, the SSIM is transformed into a reachability matrix (RM) and its transitivity is checked. Once transitivity embedding is complete, a matrix model is obtained. Then, the partitioning of the elements and an extraction of the structural model called ISM is obtained. In this approach, a methodical application of some basic concepts of graph theory is used in such a way that theoretical, conceptual and computational influence are exploited to explain the complex pattern of contextual relationship amongst a set of variables. ISM is proposed for use when desired to utilise methodical and rational thinking to approach a complex issue under deliberation. Interpretive Structural Modelling is a computer-aided method for developing graphical demonstrations of system composition and structure. ISM had its foundation in Warfield's perception of them need, when attempting to combine science to policy, for "a set of communication tools which have both a scientific and lay character serving as a linkage device between science and the public, and having sense for all who are involved" and which, in particular, are competent of communicating a generic intellect of the elements and their relations which describe system structure. Warfield specifies a set of requirements for these communication tools which include

i. $\quad$ Provision for the insertion of the systematic elements

ii. Means for demonstrating a multifaceted set of associations

iii. Means for showing that complex set of associations which permit constant scrutiny, questioning and alteration of the associations

iv. Resemblance with the designers' insights and investigative processes

v. simplicity of learning by public (or, by deduction, multidisciplinary) audience.

Graphical models or, more purposely, directed graphs (digraphs) come into sight to satisfy these conditions. In such a depiction, the elements or constituents of a system are represented by the "points" of the graph and the existence of a particular association between elements is specified by the presence of a directed line segment. It is the concept of relatedness in the context of a particular association, which differentiates a system from a simple aggregation of constituents. This methodology is interpretive as the opinion of the group decides whether and how the different elements are interrelated. It is structured on the basis of common association; an overall structure is dig out from the multifaceted set of elements. It is a modelling technique for portraying the specific relationship and overall structure in a diagraph model. It helps to oblige order and direction on the intricacy of associations amongst various elements of a system. It is largely intended as a group learning procedure, but individuals can also use it (Attri et al., 2013).

\subsection{About MICMAC(Cross-Impact Matrix Multiplication Applied to the Classification analysis) analysis}

MICMAC analysis is usually done in order to classifying the factors into four different categories. This classification is based on the driving power and dependency power of the factors. The classification helps in identification of key process enablers.

\section{Problem Identification}

- Problem in this research is to find out variables those explain reverse chain performance in relation to customer satisfaction. An extensive exploratory research has been done through the literature available to me. The study extracted the following variables which are by and large explain reverse chain performance in relation to customer satisfaction as follows, 
Table 2

Initial Factors

\begin{tabular}{|c|c|}
\hline Sr.No. & Description of the variables \\
\hline V1 & We are prepared to devote people and resources to the reverse logistics activities we conduct with this customer. \\
\hline $\mathrm{V} 2$ & Consistency of return procedure \\
\hline V3 & It is convenient to contact and reach return service personnel. \\
\hline V4 & We tell the truth to our supplier \\
\hline V5 & Filling out return form is easy for me \\
\hline V6 & We appoint contact person to process information for product recovery \\
\hline V7 & Offer meaningful guarantee to our customer \\
\hline V8 & We trust that this customer will understand any problems we have that we share with him/her \\
\hline V9 & My company aims to preserve the relationship. We have with the customers indefinitely. \\
\hline V10 & There are direct computer-to-computer links with key suppliers \\
\hline V11 & We can count on this customer taking into consideration the way his/her decisions and actions affect us \\
\hline V12 & We incur lower compliance costs with environmental regulations due to our returns handling method \\
\hline V13 & Variety of options available to me for returning product. \\
\hline V14 & We respond quickly towards the customer's return needs \\
\hline V15 & Availability of collection centres \\
\hline V16 & We compensate our customer if new product sent to replace the returned product does not arrive on time. \\
\hline V17 & We use advanced information systems to track and/or expedite shipments \\
\hline V18 & We recognize our returns policies to be liberal \\
\hline V19 & Inter-organizational coordination is achieved using electronic links \\
\hline V20 & Our strategy for dealing with returned merchandise improves our cost position relative to our closest competitors \\
\hline V21 & We use information technology-enabled transaction processing \\
\hline V22 & Real-time information \\
\hline V23 & Duties, authority, and accountability for reverse logistics are documented in policies and procedures \\
\hline V24 & We address reverse logistics issues mainly with technologies we have developed \\
\hline V25 & We are realizing cost savings because of our reverse logistics activities \\
\hline V26 & Reverse logistics program evaluations in our firm are based on written standards \\
\hline V27 & Preparing the product for return is easy \\
\hline V28 & Handle the return without customer intervention \\
\hline V29 & Written procedures and guidelines are available for most reverse logistics related work situations \\
\hline V30 & Relationship with the supplier \\
\hline V31 & Overall Satisfaction \\
\hline
\end{tabular}

- Identification of most important variables amongst these extracted variables, which explain reverse chain performance by using some scientific and proven methodology such as Factor Analysis \& Interpretive Structural Modelling with the help of interactive and contextual relationship amongst the extracted variables.

- Classification of these variables into disparate groups according to their driving power and dependency power. This helps in identification of key reverse chain performance enablers in relation to reverse chain performance.

\section{Methodology}

In this research, an ISM-based model has been used to investigate the relations amongst diverse factors which explain performance of reverse logistics. The main purpose of this research is to examine the efficacy of various factors which help in the execution of sustainability in the Reverse Chain in any industry. The methodology suggested here identifies the pecking order of actions to be taken for handling these diverse factors' ability to make reverse chain performance sustainable in relation to customer satisfaction.

\subsection{ISM Methodology}

Step 1:

Identification of factors related to proposed

\section{Step 2:}

A Structural Self-Interaction Matrix (SSIM) is developed for these factors. This matrix point outs the pair-wise associations amongst the factors of the system. This matrix is checked for transitivity.

\section{Step 3:}

Develop a Reachability Matrix (RM) from the SSIM. 
Step 4:

Partitioning of The RM into different levels

Step 5:

The Reachability Matrix is transformed into its conical form, i.e. with most zero (0) elements in the upper diagonal half of the matrix and most unitary (1) elements in the lower half.

Step 6:

A directed graph (digraph) is drawn and transitivity links are removed.

Step 7:

Digraph is converted into an ISM model

Step 8:

The ISM model is examined for theoretical discrepancy and essential adjustments are incorporated.

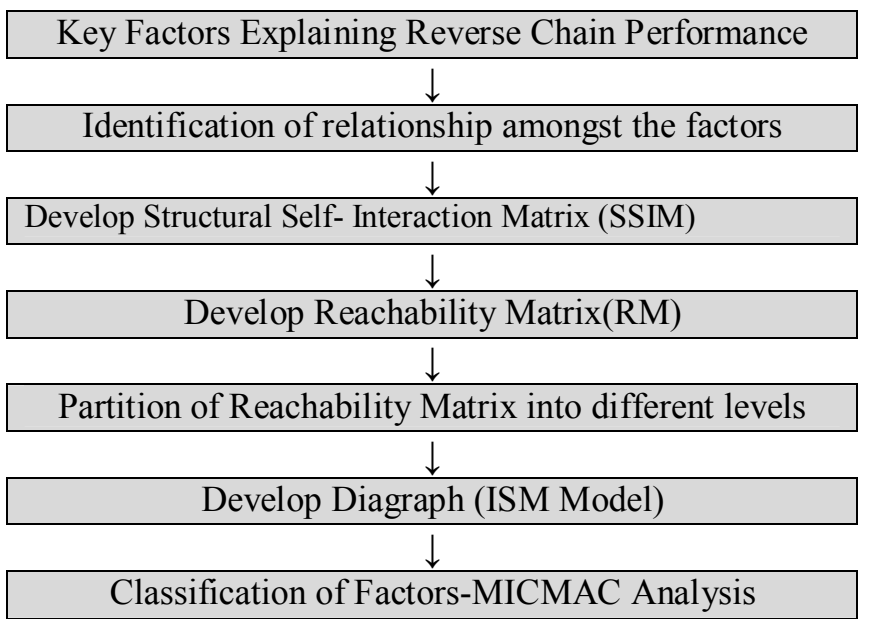

Fig. 4. Flow Chart for developing an ISM

\subsection{MICMAC Methodology}

\section{Phase 1:}

The first stage consists in listing all the factors which describe the system under study. This phase should be as meticulous as possible and at the outset should not leave out any line of research.

\section{Phase 2:}

In a systemic approach, a variable exists only through its relationship with other variables. Structural analysis thus efforts to determine the associations between factors in a dual-entry table called "structural analysis matrix".

\section{Phase 3:}

This phase consists of identifying the key factors, those indispensable to the system's development, first by using direct classification (easy to set up), then through indirect classification (MICMAC applied to a Classification). This indirect classification is found after enhancing the power of the matrix. Comparing the hierarchy of factors in the various classifications (direct, indirect and potential) is a rich source of information. It enables one not only to confirm the importance of certain factors but also to uncover certain factors, which, because of their indirect actions, play an important role (yet were not identifiable through direct classification).

\section{Data Analysis \& Interpretation}

\section{Identification of key factors}


The factors of the system are identified which are pertinent to the problem and then on the basis of the literature review/factor analysis/expert opinion, a total of 17 key factors were identified. The next step is to analyse these key factors.

\section{Table 1}

Key Factors

\begin{tabular}{cl}
\hline Sr.No. & Description of the variables \\
\hline V1 & We are prepared to devote people and resources to the reverse logistics activities we conduct with this customer. \\
V2 & Consistency of return procedure \\
V3 & It is convenient to contact and reach return service personnel. \\
V5 & Filling out return form is easy for me \\
V7 & Offer meaningful guarantee to our customer \\
V9 & My company aims to preserve the relationship. We have with the customers indefinitely. \\
V11 & We can count on this customer taking into consideration the way his/her decisions and actions affect us \\
V13 & Variety of options available to me for returning product. \\
V14 & We respond quickly towards the customer's return needs \\
V15 & Availability of collection centers \\
V16 & We compensate our customer if new product sent to replace the returned product does not arrive on time. \\
V18 & We recognize our returns policies to be liberal \\
V23 & Duties, authority, and accountability for reverse logistics are documented in policies and procedures \\
V24 & We address reverse logistics issues mainly with technologies we have developed \\
V26 & Reverse logistics program evaluations in our firm are based on written standards \\
V28 & Handle the return without customer intervention \\
V29 & Written procedures and guidelines are available for most reverse logistics related work situations \\
\hline
\end{tabular}

\subsection{Structural Self-Interaction Matrix (SSIM)}

Development of SSIM led to describe the contextual relationship between different pair of factors. Keeping in mind the contextual relationship for each factor and the existence of a relationship between any two factors (I and J), the associated direction of the relationship is examined. Four symbols are used to represent the direction of association between any two factors (I and J) are as follows:

(a) $\mathrm{V}$ for the relationship from factor I to factor $\mathrm{J}$ means I influence $\mathrm{J}$ but reverse is not true.

(b) A for the relationship from factor $\mathrm{J}$ to factor I means $\mathrm{J}$ influence I but reverse is not true.

(c) $\mathrm{X}$ for relationship between I and I in both the direction.

(d) $\mathrm{O}$ for no relation between $\mathrm{I}$ and $\mathrm{J}$

Table 2

Structural Self-Interaction Matrix (SSIM)

\begin{tabular}{|c|c|c|c|c|c|c|c|c|c|c|c|c|c|c|c|c|c|}
\hline Factors & 18 & 24 & 3 & 13 & 5 & 2 & 29 & 23 & 26 & 16 & 9 & 14 & 15 & 7 & 28 & 11 & 1 \\
\hline 1 & 0 & 0 & $\mathrm{~V}$ & $\mathrm{~V}$ & 0 & $\mathrm{~V}$ & 0 & 0 & 0 & 0 & $X$ & $\mathrm{~V}$ & $\mathrm{~V}$ & 0 & $\mathrm{~V}$ & $X$ & \\
\hline 11 & $\mathrm{O}$ & $\mathrm{O}$ & V & $\mathrm{O}$ & $\mathrm{O}$ & V & $\mathrm{O}$ & $\mathrm{O}$ & V & $\mathrm{O}$ & $X$ & $\mathrm{~V}$ & V & $\mathrm{O}$ & V & & \\
\hline 28 & $\mathrm{O}$ & $\mathrm{O}$ & V & $\mathrm{O}$ & V & V & V & $\mathrm{V}$ & $\mathrm{O}$ & $\mathrm{O}$ & A & $X$ & $\mathrm{X}$ & A & & & \\
\hline 7 & $\mathrm{O}$ & A & $\mathrm{O}$ & $\mathrm{O}$ & $\mathrm{O}$ & V & $\mathrm{O}$ & $\mathrm{O}$ & $\mathrm{O}$ & $\mathrm{X}$ & A & $\mathrm{O}$ & A & & & & \\
\hline 15 & $\mathrm{O}$ & $\mathrm{O}$ & $\mathrm{O}$ & $\mathrm{O}$ & $\mathrm{O}$ & V & $\mathrm{O}$ & V & $\mathrm{O}$ & $\mathrm{O}$ & $\mathrm{O}$ & $X$ & & & , & & \\
\hline 14 & $\mathrm{O}$ & V & $\mathrm{O}$ & A & $\mathrm{O}$ & $\mathrm{O}$ & V & $\mathrm{O}$ & V & $\mathrm{V}$ & $\mathrm{O}$ & & & & & & \\
\hline 9 & $\mathrm{O}$ & $\mathrm{O}$ & $\mathrm{O}$ & $\mathrm{O}$ & $\mathrm{O}$ & V & $\mathrm{O}$ & $\mathrm{O}$ & $\mathrm{O}$ & $\mathrm{O}$ & & & & & & & \\
\hline 16 & $\mathrm{O}$ & V & $\mathrm{V}$ & $\mathrm{V}$ & $\mathrm{O}$ & $\mathrm{O}$ & $\mathrm{V}$ & $\mathrm{V}$ & $\mathrm{X}$ & & & & & & & & \\
\hline 26 & $\mathrm{O}$ & $\mathrm{O}$ & V & $\mathrm{O}$ & V & $X$ & V & $\mathrm{O}$ & & & & & & & & & \\
\hline 23 & $\mathrm{O}$ & $X$ & $X$ & V & $\mathrm{O}$ & $\mathrm{O}$ & $X$ & & & & & & & & & & \\
\hline 29 & $X$ & V & V & V & A & V & & & & & & & & & & & \\
\hline 2 & $X$ & $\mathrm{O}$ & $\mathrm{V}$ & $\mathrm{V}$ & $\mathrm{O}$ & & & & & & & & & & & & \\
\hline 5 & A & A & $\mathrm{O}$ & A & & & & & & & & & & & & & \\
\hline 13 & $\mathrm{O}$ & $\mathrm{O}$ & $\mathrm{O}$ & & & & & & & & & & & & & & \\
\hline 3 & A & $\mathrm{O}$ & & & & & & & & & & & & & & & \\
\hline 24 & $\mathrm{O}$ & & & & & & & & & & & & & & & & \\
\hline 18 & & & & & & & & & & & & & & & & & \\
\hline
\end{tabular}

\section{Reachability Matrix}

Reachability matrix is the binary transformation of structured self-interaction matrix,

a. Presence of relationship directed from factor $\mathrm{I}$ to $\mathrm{J}$ is indicated by replacing $\mathrm{V}$ with binary equivalent 1 at the intersection between row I and column J. Putting 0 at the intersection of row $\mathrm{J}$ and column I. 
b. Presence of relationship directed from factor $\mathrm{J}$ to $\mathrm{I}$ is indicated by replacing A with binary equivalent 1 at the intersection between row $J$ and column I. Putting 0 at the intersection of row I and column J.

c. Presence of relationship directed from factor $\mathrm{I}$ to $\mathrm{J}$ and $\mathrm{J}$ to $\mathrm{I}$ is indicated by replacing $\mathrm{X}$ with binary equivalent 1 at the intersection between row I and column J. Putting 1 at the intersection of row $\mathrm{J}$ and column $\mathrm{I}$.

d. No relationship between factors $\mathrm{I}$ and $\mathrm{J}$ is indicated by replacing $\mathrm{O}$ with the binary equivalent 0 at the intersection of row I and column J. Putting 0 at the intersection of row $\mathrm{J}$ and column I.

Table 3

Reachability Matrix

\begin{tabular}{|c|c|c|c|c|c|c|c|c|c|c|c|c|c|c|c|c|c|}
\hline & 1 & 11 & 28 & 7 & 15 & 14 & 9 & 16 & 26 & 23 & 29 & 2 & 5 & 13 & 3 & 24 & 18 \\
\hline 1 & 1 & 1 & 1 & 0 & 1 & 1 & 1 & 0 & 0 & 0 & 0 & 1 & 0 & 1 & 1 & 0 & 0 \\
\hline 11 & 1 & 1 & 1 & 1 & 1 & 1 & 1 & 0 & 1 & 0 & 0 & 1 & 0 & 0 & 1 & 0 & 0 \\
\hline 28 & 0 & 0 & 1 & 0 & 1 & 1 & 0 & 0 & 0 & 1 & 1 & 1 & 1 & 0 & 1 & 0 & 0 \\
\hline 7 & 0 & 0 & 1 & 1 & 0 & 0 & 0 & 1 & 0 & 0 & 0 & 1 & 0 & 0 & 0 & 0 & 0 \\
\hline 15 & 0 & 0 & 1 & 1 & 1 & 1 & 0 & 0 & 0 & 1 & 0 & 1 & 0 & 0 & 0 & 0 & 0 \\
\hline 14 & 0 & 0 & 1 & 0 & 1 & 1 & 0 & 1 & 1 & 0 & 1 & 0 & 0 & 0 & 0 & 1 & 0 \\
\hline 9 & 1 & 1 & 1 & 1 & 0 & 0 & 1 & 0 & 0 & 0 & 0 & 1 & 0 & 0 & 0 & 0 & 0 \\
\hline 16 & 0 & 0 & 0 & 1 & 0 & 0 & 0 & 1 & 1 & 1 & 1 & 0 & 0 & 1 & 1 & 1 & 0 \\
\hline 26 & 0 & 0 & 0 & 0 & 0 & 0 & 0 & 1 & 1 & 1 & 1 & 1 & 1 & 0 & 1 & 0 & 0 \\
\hline 23 & 0 & 0 & 0 & 0 & 0 & 0 & 0 & 0 & 1 & 1 & 1 & 1 & 0 & 1 & 1 & 1 & 0 \\
\hline 29 & 0 & 0 & 0 & 0 & 0 & 0 & 0 & 0 & 0 & 0 & 1 & 1 & 0 & 0 & 1 & 1 & 1 \\
\hline 2 & 0 & 0 & 0 & 0 & 0 & 0 & 0 & 0 & 1 & 1 & 0 & 1 & 0 & 1 & 1 & 0 & 1 \\
\hline 5 & 0 & 0 & 0 & 0 & 0 & 0 & 0 & 0 & 0 & 0 & 1 & 0 & 0 & 0 & 0 & 0 & 0 \\
\hline 13 & 0 & 0 & 0 & 0 & 0 & 0 & 0 & 0 & 0 & 0 & 0 & 0 & 1 & 1 & 0 & 0 & 0 \\
\hline 3 & 0 & 0 & 0 & 0 & 0 & 0 & 0 & 0 & 0 & 1 & 0 & 0 & 0 & 0 & 0 & 0 & 0 \\
\hline 24 & 0 & 0 & 0 & 1 & 0 & 0 & 0 & 0 & 0 & 1 & 0 & 0 & 1 & 0 & 0 & 0 & 0 \\
\hline 18 & 0 & 0 & 0 & 0 & 0 & 0 & 0 & 0 & 0 & 1 & 1 & 1 & 1 & 0 & 1 & 0 & 0 \\
\hline
\end{tabular}

\section{Final Reachability Matrix:}

The reach ability matrix obtained in the previous step is converted into the final reachability matrix by checking it for transitivity. The transitivity of the contextual relation states that if element $\mathrm{A}$ is related to $\mathrm{B}$ and $\mathrm{B}$ is related to $\mathrm{C}$, then $\mathrm{A}$ is related to $\mathrm{C}$. Some of the cells are filled by inference drawn on the basis of transitivity and it is denoted by $1^{\mathrm{t}}$. By incorporating transitivity final reachability matrix is obtained. The drive power of a factor is calculated by adding the number of ones in the rows and its dependence power by adding the number of ones in the columns.

Table 4

Final Reachability Matrix

\begin{tabular}{|c|c|c|c|c|c|c|c|c|c|c|c|c|c|c|c|c|c|c|}
\hline & 1 & 11 & 28 & 7 & 15 & 14 & 9 & 16 & 26 & 23 & 29 & 2 & 5 & 13 & 3 & 24 & 18 & Driving Power \\
\hline 1 & 1 & 1 & 1 & 0 & 1 & 1 & 1 & 0 & 0 & 0 & 0 & 1 & 0 & 1 & 1 & 0 & 0 & 10 \\
\hline 11 & 1 & 1 & 1 & 1 & 1 & 1 & 1 & 0 & 1 & 0 & 0 & 1 & 0 & 0 & 1 & 0 & 0 & 9 \\
\hline 28 & 0 & 0 & 1 & 0 & 1 & 1 & 0 & 0 & $1^{t}$ & 1 & 1 & 1 & 1 & $1^{t}$ & 1 & $1^{t}$ & 0 & 11 \\
\hline 7 & 0 & 0 & 1 & 1 & 0 & $1^{t}$ & 0 & 1 & $1^{t}$ & $1^{t}$ & $1^{t}$ & 1 & $1^{t}$ & 0 & 0 & 0 & 0 & 9 \\
\hline 15 & 0 & $1^{t}$ & 1 & 1 & 1 & 1 & 0 & 0 & 0 & 1 & $1^{t}$ & 1 & 0 & $1^{\mathrm{t}}$ & 0 & 0 & $1^{t}$ & 9 \\
\hline 14 & 0 & 0 & 1 & 0 & 1 & 1 & 0 & 1 & 1 & $1^{t}$ & 1 & 0 & 0 & $1^{t}$ & 0 & 1 & $1^{t}$ & 10 \\
\hline 9 & 1 & 1 & 1 & 1 & 0 & 0 & 1 & $1^{t}$ & 0 & $1^{t}$ & 0 & 1 & 0 & $1^{t}$ & 0 & 0 & 0 & 9 \\
\hline 16 & 0 & 0 & 0 & 1 & 0 & $1^{\mathrm{t}}$ & 0 & 1 & 1 & 1 & 1 & 0 & 0 & 1 & 1 & 1 & $1^{t}$ & 10 \\
\hline 26 & 0 & 0 & 0 & 0 & 0 & 0 & 0 & 1 & 1 & 1 & 1 & 1 & 1 & $1^{t}$ & 1 & 0 & $1^{t}$ & 9 \\
\hline 23 & 0 & 0 & 0 & 0 & 0 & 0 & 0 & $1^{t}$ & 1 & 1 & 1 & 1 & $1^{t}$ & 1 & 1 & 1 & $1^{t}$ & 9 \\
\hline 29 & 0 & $1^{t}$ & 0 & 0 & 0 & 0 & 0 & 0 & $1^{t}$ & 0 & 1 & 1 & $1^{t}$ & $1^{t}$ & 1 & 1 & 1 & 9 \\
\hline 2 & 0 & 0 & 0 & 0 & $1^{t}$ & 0 & 0 & 0 & 1 & 1 & $1^{t}$ & 1 & $1^{t}$ & 1 & 1 & $1^{t}$ & 1 & 10 \\
\hline 5 & 0 & 0 & 0 & 0 & 0 & 0 & 0 & 0 & 0 & $1^{t}$ & 1 & 0 & 0 & 0 & 0 & 0 & 0 & 2 \\
\hline 13 & 0 & 0 & 0 & 0 & 0 & 0 & 0 & 0 & 0 & 0 & 0 & 0 & 1 & 1 & 0 & 0 & 0 & 2 \\
\hline 3 & 0 & 0 & 0 & 0 & 0 & 0 & 0 & 0 & 0 & 1 & 0 & 0 & $1^{t}$ & 0 & 0 & 0 & 0 & 2 \\
\hline 24 & 0 & 0 & 0 & 1 & 0 & 0 & 0 & 0 & 0 & 1 & 0 & 0 & 1 & 0 & 0 & 0 & 0 & 3 \\
\hline 18 & 0 & 0 & 0 & 0 & 0 & 0 & 0 & 0 & 0 & 1 & 1 & 1 & 1 & 0 & 1 & 0 & 0 & 5 \\
\hline Dependence & 3 & 5 & 7 & 6 & 6 & 7 & 3 & 6 & 9 & 13 & 9 & 9 & 10 & 10 & 9 & 6 & 7 & \\
\hline
\end{tabular}

\section{Level partitions:}

From the final reachability matrix, for each factor, reachability set and antecedent sets are derived. The reachability set comprises of the factor itself and the other factors that it may impact, whereas the antecedent set consists of the factor itself and the other factor that may impact it. Thereafter, the intersection of these sets is derived for all the factors and levels of different factor are determined. 
The factors for which the reachability and the intersection sets are the same occupy the top level in the ISM hierarchy. The top-level factors are those factors that will not lead the other factors above their own level in the hierarchy. Once the top-level factor is identified, it is removed from consideration. The same process is repeated to find out the factors in the next level. This process is continued until the level of each factor is found. These levels help in building the diagraph and the ISM model.

\section{Iteration: 2-5}

Table 5

Level Partition

\begin{tabular}{lcccc}
\hline S. no & Reachability Set & Attendance Set & Intersection & Level \\
\hline 1 & $14,1,11,28$ & $26,13,29,2,14,1,18,11,28$ & $14,1,11,28$ & 1 \\
2 & $14,1,28$ & $1,9,5,14,1,28,3$ & $14,1,28$ & 1 \\
3 & $14,1,11,28$ & $1,14,18,24,1,11,23,28$ & $14,1,11,28$ & 1 \\
4 & $16,15,7,9$ & $1,28,16,18,23,15,7,3,9$ & $16,15,7,9$ & 2 \\
5 & $16,15,7,9$ & $5,23,26,7,9,28,15,16$ & $16,15,7,9$ & 2 \\
\hline 6 & 16,7 & $3,9,23,16,7$ & 16,7 & 2 \\
7 & $20,29,2$ & $2,14,28,9,29,20$ & $20,29,2$ & 3 \\
\hline 8 & $23,26,29,2$ & $5,9,3,2,13,23,26,29$ & $23,26,29,2$ & 3 \\
10 & $26,23,29,2$ & $26,18,29,23,29,1,2$ & $26,23,29,2$ & 3 \\
11 & $5,3,13$ & $1,28,5,3,9,13$ & $5,3,13$ & 4 \\
12 & 13,3 & $24,1,2,9,3,14,13$ & 13,3 & 4 \\
13 & $3,5,13$ & $11,7,3,13,5$ & $3,5,13$ & 4 \\
\hline 14 & 18,24 & $1,11,28,7,18,3,24$ & 18,24 & 5 \\
\hline
\end{tabular}

\section{Diagraph}

Diagraph is the diagrammatic presentation of various factors and their interdependence. In this construction, the top level factor is positioned at the top of the digraph and second level factor is placed at second position and so on, until the bottom level is placed at the lowest position in the digraph.

\section{ISM Model}

Diagraph is transformed into ISM model by substituting factor nodes with the statement. After identification of factors at different levels, the relationships among the factors are represented by the arrow. The strategic factors in this case are: 'Liberal reverse logistics policy' (Factor 18), 'Use of technology in reverse chain management' (Factor 24). These factors are base of the ISM hierarchy. 'Liberal reverse logistics policy (Factor 18) leads to 'Easiness of filling return form' (Factor 5) and 'Use of technology in reverse chain management' (Factor 24) leads to 'Variety of options available for returning product' (Factor 13).

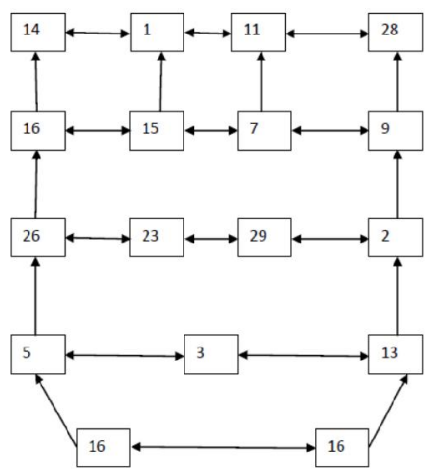

Fig. 1. ISM Model 


\subsection{MICMAC Analysis: Classification of factors}

Matrice d'Impacts croises-multiplication appliqúe an classment (cross-impact matrix multiplication applied to classification) is shortened as MICMAC. The rationale of MICMAC investigation is to analyse the driving power and dependence power of factors. MICMAC principle is based on multiplication of matrices to classify the key factors that drive the system in a variety of categories. Depending on their driving power and dependence power, the factors, have been classified into four categories i.e. autonomous factors, linkage factors, dependent and independent factors.

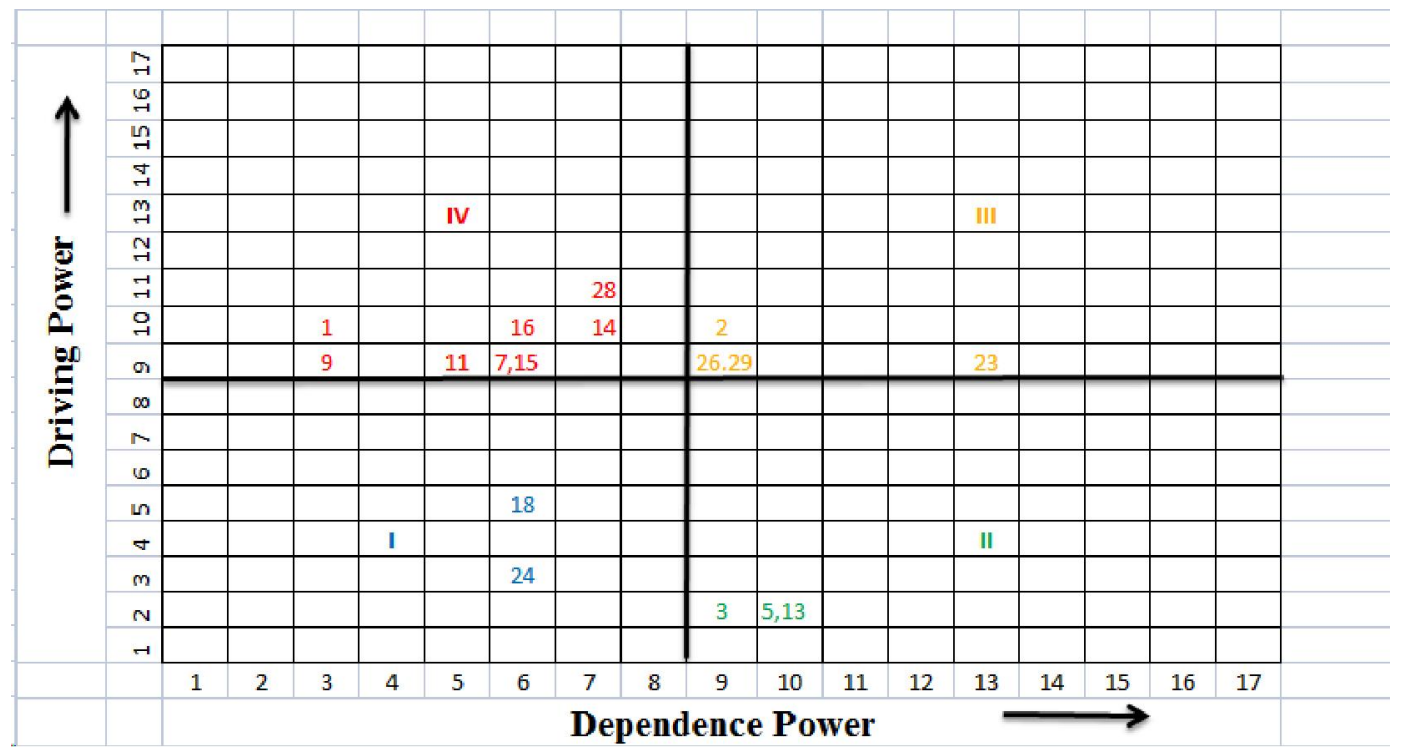

Fig. 2. MICMAC Analysis

Autonomous factors (Quadrant-I): These factors have weak driving power and weak dependence power. They are relatively disengaged from the system but they have few links, which may be very strong. Autonomous factors for this research are as follows,

- Liberal reverse logistics policy (18)

- Use of technology in reverse chain management (24)

It is quite evident that these factors by their own do not affect the performance of reverse chain in relation to customer satisfaction but they do have link to some other strong factors

Dependent factors (Quadrant-II): These factors have weak drive power but strong dependence power. The following are the dependent factors,

- It is convenient to contact and reach return service personnel. (3)

- Filling out return form is easy for me (5)

- Variety of options available to me for returning product (13)

Organization should take special care to implement these factors because of nature of the factors.

Linkage factors (Quadrant-III): These factors have strong driving power as well as strong dependence power. These factors are unstable in the fact that any action on these factors will have an effect on others and also a feedback effect on themselves. The following are the linkage factors-

- Consistency of return procedure (2)

- Written procedures and guidelines are available for most reverse logistics related work situations (29) 
- Duties, authority, and accountability for reverse logistics are documented in policies and procedures (23)

- Reverse logistics program evaluations in our firm are based on written standards (26)

If these factors are taken care off in right manner will create positive reverse chain process in relation to customer satisfaction.

Independent factors (Quadrant-IV): These factors have strong drive power but weak dependence power. A factor with a very strong drive power, called the 'key factor' falls into the category of independent factors. The following are the independent factors---

- We are prepared to devote people and resources to the reverse logistics activities we conduct with this customer (1)

- We compensate our customer if new product sent to replace the returned product does not arrive on time. (16)

- Offer meaningful guarantee to our customer (7)

- My company aims to preserve the relationship. We have with the customers indefinitely $(9$

- We can count on this customer taking into consideration the way his/her decisions and actions affect us (11)

- We respond quickly towards the customer's return needs (14)

- Availability of collection centres (15)

- Handle the return without customer intervention (28)

These are the key factors and one should include all these factors for the successful reverse chain strategy implementation.

\section{Conclusion \& Limitation}

Interpretive Structural Modelling (ISM), facilitates a systematic, directional structure for composite issues, and gives decision makers a practical picture of the situation and the factors explaining the issue. The ISM process involves the identification of factors, the definition of their interactions, and the hierarchical diagram to light up a complex issue in a systematic manner. ISM process converts vague ideas into systematic, visible and well defined models. These models help in identification of the strategic factor related to problem or issue. After identification of strategic factor, strategy may be formulated for dealing the issue.

ISM method is comprehensible to a different users in the interdisciplinary groups, presents a medium of consolidating the different insights of participating groups. It is competent in handling a large number of factors, their interrelationships pertaining to complex issues and depicting the system behaviour. ISM is also easy to use and meant for a larger audience.

In this research total 30 factors were taken to model the reverse chain performance in relation to customer satisfaction. After doing the extensive exploratory research through the literature available to me and interviewing the experts in line with the research, these 30 factors have reduced to manageable 17 variables. This helped us in constructing the ISM model. The strategic factors in this case are: 'Liberal reverse logistics policy' (Factor 18), 'Use of technology in reverse chain management' (Factor 24). These factors are base of the ISM hierarchy. These factors may help in strategy formulation for the reverse chain process which is centred around the issue of customer satisfaction. The classification of factors into four separate clusters according to their driving influence and dependence power will further help in identification of key factors which are absolutely essential in successful implementation of the strategy. These key factors are independent in in nature having strong driving power and weak dependence. The following are the key factors- 
- We are prepared to devote people and resources to the reverse logistics activities we conduct with this customer (1)

- We appoint contact person to process information for product recovery (6)

- Offer meaningful guarantee to our customer (7)

- My company aims to preserve the relationship. We have with the customers indefinitely (9)

- We can count on this customer taking into consideration the way his/her decisions and actions affect us (11)

- We respond quickly towards the customer's return needs (14)

- Availability of collection centres (15)

- Handle the return without customer intervention (28)

\section{Limitation of ISM Model}

- ISM is based on static or structured interrelationship amongst the factors.

- ISM methodology is based on qualitative factors and can pose plenty of problems during the implementation. Model is often blamed for being simplistic.

\section{References}

Andel, T. (1997). Reverse logistics: a second chance to profit. Transportation \& Distribution, 38(7), 61.

Autry, C. W., Daugherty, P. J., \& Richey, R. G. (2001). The challenge of reverse logistics in catalog retailing. International Journal of Physical Distribution \& Logistics Management, 31(1), 26-37.

Attri, R., Dev, N., \& Sharma, V. (2013). Interpretive structural modelling (ISM) approach: an overview. Research Journal of Management Sciences, 2(2), 3-8.

Blanchard, D. (2005). Moving forward in reverse. Logistics Today, 46(7).

Blumberg, D. F. (1999). Strategic examination of reverse logistics and repair service requirements, needs, market size, and opportunities. Journal of Business Logistics, 20, 141-159.

Bowersox, D. J., \& Daugherty, P. J. (1992). Logistics leadership-logistics organizations of the future. Logistics Information Management, 5(1), 12-18.

Bowersox, D. J. (1992). Logistical excellence: it's not business as usual. Digital Pr.

Carter, C. R., \& Ellram, L. M. (1998). Reverse logistics: A review of the literature and framework for future investigation. Journal of Business Logistics, 19(1), 85-103.

Clegg, A. J., Williams, D. J., \& Uzsoy, R. (1995, May). Production planning for companies with remanufacturing capability. In Electronics and the Environment, 1995. ISEE., Proceedings of the 1995 IEEE International Symposium on (pp. 186-191). IEEE.

Clendenin, J. A. (1997). Closing the supply chain loop: Re-engineering the returns channel process. International Journal of Logistics Management, 8(1), 75-85.

Daugherty, P. J., Myers, M. B., \& Richey, R. G. (2002). Information support for reverse logistics: the influence of relationship commitment. Journal of Business Logistics, 23(1), 85-106.

Dowlatshahi, S. (2000). Developing a theory of reverse logistics. Interfaces, 30(3), 143-155.

Farris, D. R., \& Sage, A. P. (1975). On the use of interpretive structural modeling for worth assessment. Computers \& Electrical Engineering, 2(2), 149-174.

Fleischmann, M., Bloemhof-Ruwaard, J. M., Dekker, R., Van Der Laan, E., Van Nunen, J. A., \& Van Wassenhove, L. N. (1997). Quantitative models for reverse logistics: a review. European journal of operational research, 103(1), 1-17.

French, M. L., \& Discenza, R. (2006). Returns in process industries: a managerial perspective. Management Research News, 29(12), 769-781.

Giuntini, R., \& Andel, T. (1995). Reverse logistics role models: Part 3.Transportation and Distribution, 36(4), 97-98.

Green, K., Morton, B., \& New, S. (1998). Green purchasing and supply policies: do they improve companies' environmental performance?. Supply Chain Management: An International Journal, 3(2), $89-95$. 
Heine, H., \& Byrne, P. M. (1993). Reducing waste through reverse logistics. Foundry Management \& Technology, 121(8), 28.

Klausner, M., \& Hendrickson, C. T. (2000). Reverse-logistics strategy for product takeback. Interfaces, 30(3), 156-165.

Krupp, J. A. (1993). Structuring bills of material for automotive remanufacturing. Production and Inventory Management Journal, 34, 46-46.

Mason, S. (2002). Backward progress. IIE solutions, 34(8), 42-46.

Merritt, K. (2001). Integrated reverse logistics solution allows Levi Strauss to profit off returns. Frontline Solutions, 2, 41.

Mollenkopf, D., Russo, I., \& Frankel, R. (2007). The returns management process in supply chain strategy. International Journal of Physical Distribution \& Logistics Management, 37(7), 568-592.

Murray, J. G. (2000). Effects of a green purchasing strategy: the case of Belfast City Council. Supply Chain Management: An International Journal, 5(1), 37-44.

Raj, T., Shankar, R., \& Suhaib, M. (2008). An ISM approach for modelling the enablers of flexible manufacturing system: the case for India. International Journal of Production Research, 46(24), 68836912.

Ravi, V., \& Shankar, R. (2005). Analysis of interactions among the barriers of reverse logistics. Technological Forecasting and Social Change, 72(8), 1011-1029.

Richey, R. G., Chen, H., Genchev, S. E., \& Daugherty, P. J. (2005). Developing effective reverse logistics programs. Industrial Marketing Management, 34(8), 830-840.

Ritchie, L., Burnes, B., Whittle, P., \& Hey, R. (2000). The benefits of reverse logistics: the case of the Manchester Royal Infirmary Pharmacy. Supply Chain Management: An International Journal, 5(5), 226-234.

Richey, R. G., Genchev, S. E., \& Daugherty, P. J. (2005). The role of resource commitment and innovation in reverse logistics performance. International Journal of Physical Distribution \& Logistics Management, 35(4), 233-257.

Rogers, D. S., \& Tibben-Lembke, R. (2001). An examination of reverse logistics practices. Journal of business Logistics, 22(2), 129-148.

Rogers, D. S., \& Tibben-Lembke, R. S. (1999). Going backwards: reverse logistics trends and practices (Vol. 2). Pittsburgh, PA: Reverse Logistics Executive Council.

Rogers, D. S., \& Tibben-Lembke, R. S. (2000). Going backwards: reverse logistics trends and practices (Vol. 2). Pittsburgh, PA: Reverse Logistics Executive Council.

Ruekert, R. W., Walker Jr, O. C., \& Roering, K. J. (1985). The organization of marketing activities: a contingency theory of structure and performance. The Journal of Marketing, 49, 13-25.

Sage, A. (1977). Interpretive structural modeling: methodology for large-scale systems, 91-164.

Singh, M. D., Shankar, R., Narain, R., \& Agarwal, A. (2003). An interpretive structural modeling of knowledge management in engineering industries. Journal of Advances in Management Research, 1(1), 28-40.

South, S. (1998). Managing returned freight. Inbound Logistics, 18(12), 48-49.

Trebilcock, B. (2002). The seven deadly sins of reverse logistics. Logistics Management and Distribution, $56(3), 5$.

Stock, J. R. (1998). Development and implementation of reverse logistics programs. Oak Brook, IL7 Council of Logistics Management.

Van Hoek, R. I. (1999). From reversed logistics to green supply chains. Supply Chain Management, 4, $129-134$.

Van de Ven, A. H., \& Ferry, D. L. (1980). Measuring and assessing organizations. New York7 Wiley and Sons.

Warfield, J.W. (1974). Developing interconnected matrices in structural modeling. IEEE Transactions on Systems Men and Cybernetics, 4(1), 51-81.

Walker Jr, O. C., \& Ruekert, R. W. (1987). Marketing's role in the implementation of business strategies: a critical review and conceptual framework. The Journal of Marketing, 51, 15-33.

White, J. A. (1994). Reverse logistics moves forward. Modern Materials Handling, 49(1), 29.

Zeiger, A. (2003). Reverse logistics: the new priority? Frontline Solutions, 4(11), 20. 